\title{
Focusing on SMTEs: Using Audience Response Technology to Refine a Research Project
}

\author{
David A Banks \\ Central Connecticut State \\ University, \\ New Britain, CT, USA \\ traveldab@gmail.com
}

\author{
Ann Monday \\ Newcastle Business School, \\ Northumbria University, \\ Newcastle upon Tyne, UK \\ ann.monday@northumbria.ac.uk
}

\author{
Stephen Burgess and Carmine Sellitto \\ Centre for Tourism and Services Research, Victoria University, \\ Melbourne, Australia \\ stephen.burgess@vu.edu.au; carmine.sellitto@vu.edu.au
}

\begin{abstract}
This paper reports on the use of audience response technology to support a focus group session that was conducted as the first phase of a study exploring the use of ICTs in small to medium tourism enterprises (SMTEs) in the Australian States of South Australia and Victoria. A variety of large and small group support technology was considered before the audience response technology was adopted. The paper explores the way that such technologies can be used to successfully support research that utilises focus groups. Valuable lessons were learned from the first focus group session and the outcomes informed the subsequent semi-structured interviews.
\end{abstract}

Keywords: SMTE, tourism, audience response system, focus groups, Australia

\section{Introduction}

This paper reports on one aspect of a broader research scheme that involved exploring the way that small and medium-sized tourism industries (SMTEs) in Australia were dealing with the growing impact of information and communication technologies (ICTs). The long-term aim of the research was to develop a 'toolkit' that would help support SMTEs to explore the risks, benefits and adoption strategies for ICTs. The overall outcomes of the research have been reported in detail elsewhere (Burgess, Sellitto, Banks, \& Monday, 2009; Monday, Burgess, Sellitto, \& Banks 2009; Sellitto, Banks, Monday, \& Burgess, 2009) and are therefore not included here. This paper specifically reports upon the use of audience response technology to support the focus group as-

Material published as part of this publication, either on-line or in print, is copyrighted by the Informing Science Institute. Permission to make digital or paper copy of part or all of these works for personal or classroom use is granted without fee provided that the copies are not made or distributed for profit or commercial advantage AND that copies 1) bear this notice in full and 2) give the full citation on the first page. It is permissible to abstract these works so long as credit is given. To copy in all other cases or to republish or to post on a server or to redistribute to lists requires specific permission and payment of a fee. Contact 0HPublisher@InformingScience.org to request redistribution permission. pect of the data gathering phase of the research.

Tourism is an industry dominated by information, with decision-making increasingly influenced by a number of commonly accessible sources such as television, brochures, word-of-mouth and the Internet. It has been suggested that the tourism industry and the Internet are particularly suited to each other, giv- 
en that tourism is an information-based and information-intensive sector (Werthner \& Ricci 2004). Where an industry has a strong information component, ICTs can be used as one possible means of gaining competitive advantage. The number of people that use the Internet to research, plan and transact their trips is increasing. In fact, the Internet "has become one of the most successful channels used by consumers to research travel options, compare prices and make reservations" (Collins, Buhalis, \& Peters 2003, p. 484). Arguably, the history of the tourism industry is one of adopting and using technologies, such as computerised reservation systems (CRS) and global distribution systems (GDS), that are integral to travel agency and airline functionality (Liu, 2000). The tourism industry is also beginning to embrace mobile technologies with the use of devices such as handheld computers, mobile phones and personal digital assistants (PDA). Mobile devices can provide advantages such as portability, immediacy and even 'location aware' contextualised information. In fact, whilst 'mobile commerce' (m-commerce) may be viewed as an add-on in other sectors, it may become a vital component of the tourism industry (Lee \& Mills, 2007).

The specific aspect of the research considered in this paper relates to rural and metropolitan SMTEs in the Australian States of South Australia and Victoria in 2007/8. The purpose of this part of the overall study was to explore the level of awareness that SMTEs had of the range of ICTs currently available and to identify practical issues relating to adoption and use. This information was to be used to help inform the design of the eventual web-based 'toolkit' to be developed as a way of helping SMTEs gain access to appropriate information that would support their day-to-day use of ICTs, to share experiences and practice and also to suggest possible new ICT opportunities in the tourism sector. The initial phase of the research set out to identify problems, benefits and practices with the use of ICTs in SMTEs in the two States. Semi-structured interviews were used for the latter part of the research following, and informed by, initial work with focus groups. Semi-structured interviews utilise an interview guide containing a list of questions and prompts that help to manage the interview in a flexible and conversational manner around the key themes of interest (Minichiello, Aroni, Timewell, \& Alexander, 1990).

As preparation for the focus groups and subsequent interviews an initial survey of the literature was undertaken by team members supported by research assistants in both States and this identified a number of ICT and business-related areas that were felt to be important for exploration in the context of Australian SMTEs. Based upon the literature and discussion between team members the initial broad areas were refined into topics that were felt to be important for exploration.

The broad themes that emerged from the literature and the discussions were:

- Business demographics

- Use and familiarity with ICT

- Use of ICTs in operational areas

- Modes for internal and external business communication

- ICT skills

The areas of interest or specialisms of individual team members were identified and each member developed a number of questions within the broad themes. These were refined and negotiated into what was felt to be an acceptable number of questions that allowed each team member to gain specific insights from the work while at the same time providing a comprehensive view of the overall state of SMTEs in relation to their adoption and use of ICTs. These questions were developed into a semi-structured interview guide. Before embarking on the major part of the research it was decided that focus groups would provide a useful way to verify that the identified areas were indeed of concern to SMTEs and to identify any other areas of interest. 


\section{Focus Groups}

A focus group comprises a small, informal collection of individuals specifically chosen and brought together to discuss a single topic, in this case the role of ICTs in SMTEs, under the guidance of a moderator who encourages participants to freely express feelings, attitudes and ideas about the topic (Vaughn, Schumm, \& Sinagub, 1996). The topic should be narrow and engage the interest of the participants so that they are more likely to provide concrete answers and high levels of detail, with the emphasis being placed upon interaction within the group itself rather than between the facilitator and the group (Merton, Fiske, \& Kendall, 1956). In the case of this research we attempted to achieve interaction between the facilitator and the group and also promote interaction within the group.

Bruseberg and McDonagh-Philp (2001) comment that a defining characteristic of a focus group is the synergy that emerges as a result of the interaction between participants as they engage with each other in sharing or comparing ideas. One aim of the research process was to try to provide participants with opportunities to learn from each other and share problems and practice so that they derived benefits from being involved in the research.

Focus groups can be used at any stage in a research program. They can be used to explore qualitative areas where the phenomenon of interest is ill-defined or later in the program to help gain deeper insights about the views of a selected population (Seale, McCreadie, Turner-Smith, \& Tinker, 2002; Tipping, 1998). In this case they were used at the early stage of the research to test whether our semi-structured interview guide, developed from the literature, was relevant to the target population.

The focus group process is defined by Kreuger $(1994$, p. 6) as "a carefully planned discussion designed to obtain perceptions on a defined area of interest in a permissive, non-threatening environment." Bender and Ewbank (1994) indicate that focus groups can be used to explore themes that are not well known to the researchers or to elicit opinions on known topics. In this research both aspects were represented, the main emphasis being upon the use of ICTs based around the understandings of the researchers, but it also permitted the participants to raise issues that possibly had not been detected in the literature search or were assumed by the researchers on the basis of their own understanding of the area or were specific to their sector of tourism.

Bender and Ewbank regard the primary role of the facilitator as being able to create "a nonevaluative environment in which group members feel free to express their opinions without concern for the agreement or disagreement of others in the group". Templeton (1987) describes this researcher/moderator role as 'rapporteur' with Bender and Ewbank characterising the position as 'sophisticated naivete'. The objective of such stances is to create a non-judgmental environment for the participants that allows the researcher to safely raise open-ended or probing questions along the lines of 'Well, why is that?' or 'Can you tell me more about why that is so?' Despite the need to assume this enabling and group-aware role the facilitator also provides structure and timing cues for the meeting to balance the three general targets of meeting process, relationships and task outcomes (Bostrom, Anson, \& Clawson, 1993). Even when groups are carefully chosen there is always a risk that asymmetric power relationships within the group may inhibit some members from fully participating (Lewis, 1992) and a combination of careful facilitation and the use of a technology as a mediating and, arguably, anonymising tool can help to reduce any potential problem. Although anonymity is often cited as a strong attribute of decision support technologies, in the context of the small size and shared locality of the focus group in this research it was not expected to be a major factor, although care was taken to monitor and acknowledge verbal and nonverbal cues from participants and facilitator that could have impeded or distorted the process. An ice-breaker and basic data-gathering questions were used at the start of the meeting to both familiarise the participants with the technology and to reveal to them the levels of experience and spe- 
cific nature of the SMTEs represented in the group. Initial discussions about the technology and their specific businesses quickly created a sense of a communal group and the issue of anonymity, as anticipated, did not arise.

From a practical research perspective the use of focus groups offers a cost-effective approach to gathering views from a number of individuals at a single point in time and space. Consideration of the target businesses within geographic target areas suggested that we would be able to bring together perhaps five or six participants without any of them having the need to travel significant distances. (It was intended that they would be given gift vouchers to cover the cost of their petrol). Groups of six to ten participants are usually recommended but the more narrowly defined the topic, the more effective a smaller number of participants becomes (Morgan, 1988). In the case of this specific research this suggested that a total of four focus group meetings (two in each State) would be appropriate. Delays in the project that lay outside the control of the research team meant that the planned focus group meetings had to be moved to December which collided with peak business times for the SMTEs. The focus group activity was therefore reduced to two meetings in Victoria with a revised strategy being used for South Australia.

In addition to providing useful data for the researchers it was felt that the focus group members would also benefit because the group process would allow participants to see how other local SMTEs were managing their ICTs and provide a forum to discuss a variety of issues that may not have been identified by the researchers.

The first author of this paper had considerable experience in facilitating student and consultancy meetings using a variety of group support and audience response technologies (Banks, 2001a, 2001b; Banks \& Bateman, 2004; Banks \& Monday, 2006; Banks \& Wheeler, 2007) and it was decided that technology-supported focus groups would provide a practical, useful, interesting and safe vehicle to support one aspect of the research.

\section{The Technology}

Group decision support systems appear in a number of guises, from laboratory-based installations that use complex software through to small systems that are essentially electronic voting systems. The larger systems are traditionally associated with group processes that cover all stages in problem solving or decision making by utilising tools that support brainstorming, idea organisation, idea evaluation and voting. Every participant has a full alphanumeric keyboard through which they can enter views, opinions or data. If brainstorming activities are used the process gain achieved by these systems arises from the ability of every participant to work in parallel with every other thus increasing productivity as well as reducing the losses associated with turn-taking, attention blocking and so on.

In the initial research design consideration was given to the choice of systems potentially available. A full text entry laptop-based network using freely available software that could have supported five participants was considered but this was discounted because it was felt it would be potentially too complex to set up and would also place potentially high demands on the skills of the participants. These systems place the technology in a potentially rather dominant role due to their high visibility, producing a 'Kilroy' effect where participants strain to see over and around the technology (Lewe \& Kreniar, 1999). From a purely practical perspective, it was felt that failure of the fairly complex networked technology would have a damaging impact upon the group process and that appropriate contingency plans would make the exercise overly complicated.

By contrast, smaller systems are available that utilise simple, non-intrusive hand-held devices that allow limited data entry, for example 1-10 or A-J, via a small keypad. These therefore deal with only a limited spectrum of the total decision or group support processes and are typically restricted to simple voting activities. In practice the aggregated data that is readily captured using 
such simple technology can be used to trigger discussions once it is displayed on a public screen. It has to be noted here that there is a strong trend towards portable devices that offer small size, good screen quality and full text entry and these bridge the space between the existing large and small systems. Technologies such as PDAs, mobile phones and other portable communication devices increasingly occupy this space. Although the idea of using such emergent applications was attractive it was rejected due to the difficulty of obtaining the appropriate and reliable technology.

Audience Response Systems (ARS) are easily portable group-support systems that allow participants to use a small hand-help keypad to express their opinions on a range of options that are presented to them on a public screen. The use of such technologies with focus groups is not a new development, Easton, Easton and Belch (2003) suggesting that use by Cohen of hand-held devices in 1985 to gauge audience reaction to commercials was one of the first examples of such use. The technology can be regarded as being low-threat in the sense that it is unobtrusive and requires no more skill than is required to use a TV remote control. In the system available to the first author questions are presented through PowerPoint supported by an appropriate piece of software, in this case TurningPoint. Data can be captured from participants, aggregated and then displayed immediately after results have been received for discussion. The captured data can be exported to standard spreadsheet applications for more detailed analysis after meetings if required. Minimal set-up time is required at the focus group venue and contingency planning is less arduous. A thirty keypad system was available to the first author as part of his broader interest in ARS as teaching and consultancy tools and this was finally decided upon as the most appropriate technology.

No matter what technology is utilised there needs to be an underlying process structure around which the meeting is conducted. Meetings are designed around agendas and these are used by a facilitator to ensure that participants are helped to allocate their time to the various stages of the process in a timely and organised manner. The semi-structured interview guide was used to form the basis for the definition of the agenda but the key lessons determined by Nunamaker, Briggs, Mittleman, Vogel and Balthazard (1996) from their extensive use of such systems were also kept in mind. The most important of these lessons are to carry out thorough pre-session planning, and to ensure that the group is always aware of where the session is going and what relevance each activity has in achieving that goal. Although detailed session planning is required it must also be anticipated that the process itself will change the designed agenda, requiring some agility on the part of the facilitator to allow freedom but still ensure that the research objectives are achieved within the allotted time. Although technology is a key element in supporting the meeting there is a need to blend the technology with the naturalistic human communication processes.

\section{Focus Groups in Practice}

The Victorian members of the research group offered to arrange the first two focus groups to coincide with a conference that was being held in Melbourne at which the South Australian members were presenting papers. One meeting was to be held in a rural area and one in the city of Melbourne. The first focus group was held at a small rural town north of Melbourne on $30^{\text {th }}$ November 2007. It had been hoped to organise the focus group earlier than this but various, as indicated earlier, delays in the project dictated that this was the only viable date. A significant problem that emerged was that a meeting so close to Christmas impacted negatively upon small businesses preparing for the season and it became difficult to recruit a group of the eight to ten size anticipated. However, on the designated evening of the first focus group meeting a total of five businesses attended. The businesses present included Accommodation, Event, Tour, Attraction and a coffee shop and health spa that was categorised as 'Other'. It should be noted that this group had been hand-selected by a local contact. 


\section{The Meeting}

The meeting was based around 38 slides, including four that introduced the agenda and the process, and ran for a little over two hours, longer than anticipated one to one and half hours, but the participants were clearly engaged in the process. All participants came to the session directly from work and the session therefore incorporated a refreshment break. None of the participants had previously used or seen audience response technologies although one commented that he had seen it used on a TV quiz program. One participant was initially cautious about using the technology but quickly became comfortable after he had used it for the 'ice-breaker' questions and had an opportunity to ask how it worked.

Of the thirty-four PowerPoint slides used to actively support the session five were discussiononly prompts with the discussion being tape recorded for later transcription. The semi-structured questions contained in these slides provided the basis for reasonably free-ranging discussion, with the facilitator intervening by presenting the next slide when the discussion appeared to be moving too far off-topic. The remaining slides were used mainly for direct data capture through the ARS with tape recording of any surrounding discussion. The session structure allowed the participants to have some freedom to explore topics that may have been off-topic for the research but supported group cohesion, whilst at the same time staying within the research bounds of the timeconstrained semi-structured session. Figure 1 shows examples of data capture/discussion and discussion only slides.

\begin{tabular}{|c|c|}
\hline How long have you been using ICTs in your business? & Discussion \\
\hline $0 \%$ 1. We don't & \multirow{6}{*}{$\begin{array}{l}\text { - How do you gauge how successful your ICT is? } \\
\text { Do you use any formal measures to help you } \\
\text { gauge the success, or otherwise, of your ICT } \\
\text { investments? }\end{array}$} \\
\hline $14 \% 2$. Less than one year & \\
\hline $57 \% 3.1-2$ years & \\
\hline $29 \%$ 4. $3-5$ years & \\
\hline $0 \%$ 5. $6-10$ years & \\
\hline $0 \%$ 6. More than 10 years & \\
\hline
\end{tabular}

Figure 1: Examples of Data Capture and Discussion slides

In addition to recording the meeting (with the agreement of the participants) one of the researchers also took notes either when they heard or saw something that they felt would be useful and that would not be captured by the tape, or whenever the facilitator suggested that a note be taken. The use of the audience response technology allowed the facilitator to let the conversation move some distance away from the research agenda but a gentle interjection of 'Let's have a look at this slide...' would bring them back onto the themes that the researchers wished to discuss.

A subsequent de-brief session between the researchers allowed the direct data to be considered along with the additional meeting notes and a transcript of the meeting. The new insights gained from the focus group session helped to more clearly frame the subsequent research and new questions were added and several existing ones were deleted or modified. For example, we had not anticipated that participants would be running more than one business but two of the participants were in this position. This proved helpful in framing the interview guide for use with later subjects. It also became clear that although security and backup of data were recognised as important issues they were not being managed well and there was a lack of clarity about some procedures, 
for example incremental backup. Findings such as this fed forward to support the development of the practical online toolkit that the research was ultimately seeking to produce.

What was also evident was that these SMTEs recognised the importance of technologies as having the potential to support both the day to day and the strategic development of their businesses. They would have little hesitation in adopting new technologies, even given their limited technical knowledge, if it could be demonstrated that it would offer them tangible return on investment. Some of the approaches being developed by this group utilised EBay auctions, wifi hotspots etc and demonstrated a keenness to bring new technological opportunities into alignment with their business operations. The meeting process itself, being largely 'conversational' in nature, generated a number of ideas between the participants for potential future cooperative efforts that could capitalise on web-oriented technologies to create new opportunities between the various enterprises. The outcome of this meeting thus proved to be beneficial for both the researchers and the participants.

A second focus group meeting was arranged in Melbourne city centre on the following the first meeting to survey city-based SMTEs. Although those contacted agreed to attend the meeting it failed to run due to a combination of peak business demand leading to a limited number of participant withdrawals and an unanticipated traffic event in the city on that day that led to problems of access to the venue.

\section{Conclusion}

The lessons learned from the comments of the first focus group members combined with the difficulty with the second focus group clearly indicated that, however attractive the approach is, it may not always be a viable option with SMEs at particular times of the year. The remainder of research plan was therefore adjusted to recognise and accommodate the availability of individual SMTEs, with the interviewers travelling to each business instead of the businesses travelling to a focus group. This increased the costs and time required to carry out the work, but the valuable insights provided by the initial focus group members meant that the researchers had confidence in the interview guide for the remaining subjects.

The conversation between the participants was lively and they appreciated the opportunity to meet and exchange experiences and ideas. There was considerable sharing of ideas and a recognition that technology offered potential opportunities for future collaboration between the various local businesses. In the refreshment break it was possible for the researchers to talk with individuals and to answer any specific ICT issues that they raised, offering guidance wherever appropriate. More generally it provided an opportunity for the Victorian researchers to point out that students represented a valuable resource for businesses and to establish a point of contact.

For the researchers the new insights gained from the focus group session helped to more clearly frame the subsequent research and new questions were added and several existing ones were deleted or modified for the subsequent one-to-one interviews with the remaining SMTEs in the study.

Focus groups have a part to play at many points in research processes. Using facilitated technology-supported meetings provides a structured way to explore issues that are of interest to researchers and the participants and to capture useful data. One lesson learned from this experience is that recruitment for focus groups, and indeed for any direct research intervention, needs to take careful account of the environment within which small businesses operate.

The utilisation of a technology supported focus group provided significant opportunities and benefits for both researchers and participants and should future research circumstances be appropriate we would not hesitate to use the approach again. 


\section{Acknowledgments}

The authors wish to thank the Sustainable Tourism Cooperative Research Centre (STCRC) as the funding sponsor of this research.

\section{References}

Banks, D. A. (2001a). A critical reflection on the value of course evaluation questionnaires: Using group support tools to explore student evaluations. Information Resources Management Association conference, Toronto, May 2001

Banks, D. A. (2001b). The role of counselling-related strategies in the facilitation of electronic meetings. 6th International Conference of the International Society for Decision Support Systems, Brunel University, UK.

Banks, D. A., \& Bateman, S. (2004). Audience response systems in education: Supporting a 'lost in the desert' learning scenario. International Conference on Computers in Education (ICCE2004, Acquiring and Constructing Knowledge Through Human-Computer Interaction: Creating New Visions for the Future of Learning), Melbourne.

Banks, D. A., \& Monday, A. (2006). Audience response systems in practice: Improving Hong Kong students' understanding of decision support systems. Australasian Society for Computers in Learning in Tertiary Education (ASCILITE) Conference, Sydney.

Banks, D. A., \& Wheeler, S. (2007). Using technology to support sensitive group processes: An ethical retrospective. The Third Asia-Pacific Computing and Philosophy Conference (APCAP2007), Chulalongkorn University, Thailand.

Bender, D. E., \& Ewbank, D. (1994). The focus group as a tool for health research: Issues in design and analysis. Health Transition Review, 4(1).

Bostrom, R. P., Anson, R., \& Clawson, V. K. (1993). Group facilitation and group support systems. In L. M. Jessup \& J. S. Vallacich (Eds.), Group support systems: New Perspectives (pp.146- 168). New York: Macmillan Publishing Company.

Bruseberg, A., \& McDonagh-Philp, D. (2001). Focus groups to support the industrial/product designer: A review based on current literature and designers' feedback. Applied Ergonomics, 33, $27-38$.

Burgess, S., Sellitto, C., Banks, D. A., \& Monday, A. (2009). The use of information and communication technologies in SMTEs: The effect of varying levels of expertise. 4th International Scientific Conference 'Planning for the future - learning from the past: contemporary developments in tourism, travel \& hospitality', Rhodes Island, Greece.

Collins C., Buhalis D., \& Peters M. (2003). Enhancing SMTEs' business performance through the Internet and e-learning platforms. Education and Training, 45 (8/9), 483-494.

Easton, G., Easton, A., \& Belch, M. (2003). An experimental investigation of electronic focus groups. Information \& Management, 40, 717-727.

Kreuger, R. A. (1994). Focus groups: A practical guide for applied research (2nd ed.). London: Sage.

Lee, J., \& Mills, J. (2007). Exploring tourist satisfaction with mobile technology. Information and Communication Technologies in Tourism. Vienna: Springer. pp. 141-152.

Lewe, H., \& Kreniar, H. (1999). The design process for a computer-supported cooperative work research laboratory: The Hohenheim CA Team room. Journal of Management Information Systems, 8(3), 69.

Lewis, A. (1992). Group child interviews as a research tool. British Educational Research Journal, 18, 413-421.

Liu, Z. (2000). Internet tourism marketing: Potential and constraints. Fourth International Conference, "Tourism in Southeast Asia \& Indo-China: Development, Marketing and Sustainability". June 24-26. Chiang Mai, Thailand 
Merton, R. K., Fiske, M., \& Kendall, P. (1956). The focused interview. Glencoe, Illinois: Free Press.

Minichiello, V., Aroni, R., Timewell, E., \& Alexander, L. (1990). In-depth interviewing: Researching people. Melbourne: Longman Chesire.

Monday, A., Burgess, S., Sellitto, C., \& Banks, D. A., (2009). A study of South Australian small to medium-sized tourism enterprises (SMTEs) and their adoption of information and communication technologies (ICTs). Small Business and Entrepreneurship Conference, Liverpool.

Morgan, D. L. (1988). Focus groups as qualitative research. Newbury Park: Sage Publications.

Nunamaker, J. F., Briggs, R.O, Mittleman, D. D., Vogel, D. R., \& Balthazard, P. A. (1996). Lessons from a dozen years of group support systems research: A discussion of lab and field findings. Journal of Management Information Systems, Winter 1996-97, 13(3), 163-207.

Seale, J., McCreadie, C., Turner-Smith, A., \& Tinker, A. (2002). Older people as partners in assistive technology research: The use of focus groups in the design process. Technology and Disability, 14, 21-29.

Sellitto, C., Banks, D. A., Monday, A., \& Burgess, S. (2009). A study of Australian small to medium tourism enterprises and their ICT adoption. International Journal of Knowledge, Culture \& Change Management, 9(6), 1-14.

Templeton, J. F. (1987). Focus groups: A guide for marketing and advertising professionals. Chicago: Probus Publishing.

Tipping, J. (1998). Focus groups: A method of needs assessment. Journal of Continuing Education in the Health Professions, 18(3), 150-154.

Vaughn, S., Schumm, J. S., \& Brown, L. F. (1991). Focus group interviews in education and psychology. London: Sage.

Werthner, H., \& Ricci, F. (2004). Tourism and development II: E-commerce and tourism. Communications of the ACM, 47(12), 101-105.

\section{Biographies}

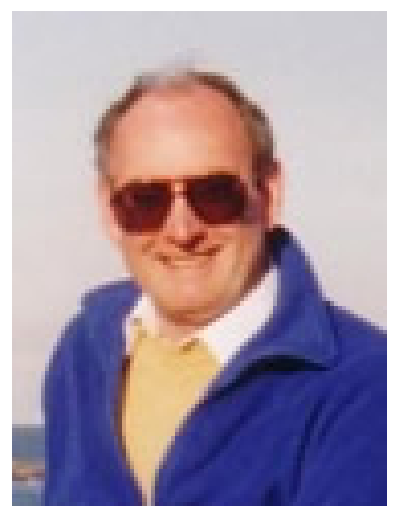

David A. Banks has practical and research interests in Audience Response Systems (ARS) and he has used this technology to support teaching, research and consultancy since 1995 . He edited a book exploring the use of ARS in higher education in 2006. He was a Visiting Research Scholar at Central Connecticut State University in late 2009. $\mathrm{He}$ is a member of the British Computer Society and a Chartered IT Professional.

Ann Monday lectures in supply chain performance at the Newcastle Business School. Her current research is in the area of supply chain management for micro, small and medium sized wine producers in the Australian wine industry. She has presented a number of papers at conferences in Australia, Finland, New Zealand, Canada, the USA, Ireland and the UK relating to both her supply chain interests and pedagogy. She is also on the editorial board and reviews for a number of journals. 


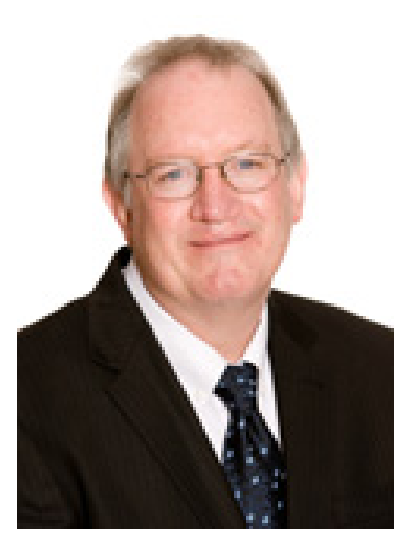

Stephen Burgess is an Associate of the Centre for Tourism and Services Research (CTSR) at Victoria University. His research and teaching interests include the use of ICTs in small businesses (particularly in the tourism field), the strategic use of ICTs, and B2C electronic commerce. He has completed several studies related to website features in small businesses and how well websites function over time. He has authored/edited three books and special editions of journals in topics related to the use of ICTs in small business.

Carmine Sellitto is Research Associate with the Centre for Tourism and Services Research (CTSR) at Victoria University. He gained his $\mathrm{PhD}$ from RMIT University where he received the Business student award for innovation. Dr Sellitto has published widely and some of his 80 peer-reviewed publications have been on topics associated with ebusiness, information management and technology, tourism and IT, Internet-marketing, information quality, small business technology adoption and education. 